\title{
Papers
}

\section{Making ends meet: Target date investment funds and retirement wealth creation}

Received (in revised form): 30th July, 2008

\section{Nigel D. Lewis}

is the Chief Risk Officer at the Teacher Retirement System of Texas. His current research is focused on asset allocation in target date funds, passive risk-based lifecycle asset allocation, semi-passive hedge fund replication, intelligent portfolio optimisation, alternative assets in lifecycle investing and post-retirement optimal asset allocation.

\begin{abstract}
Despite the growing importance of target date funds as retirement accumulation vehicles, there exists a paucity of literature on their comparative risk-return characteristics. This paper develops a stochastic simulation model to capture the impact of different target date equity glide paths on retirement wealth creation. The findings are contrasted against the retirement wealth created by a typical defined benefit plan. The results have important implications for target date fund participants and plan sponsors whose fiduciary duty is to select and offer a suitable line of target date products. Pensions (2008) 13, 130-135. doi:10.1057/pm.2008.18
\end{abstract}

Keywords: target date, savings, retirement, risk, defined benefit, wealth creation

Over the past 25 years the US retirement system has experienced a substantial transformation. The introduction of the $401(\mathrm{k})$ plan in the early 1980s as a new variation of defined contribution plan changed the retirement savings landscape dramatically. Employees in $401(\mathrm{k})$ plans are expected to decide on investment allocations and manage their portfolio asset mix over time. Mutual funds, new to the market, flourished providing fierce competition for traditional insurance companies in the employer sponsored retirement market. Over the period 1985-2002, the number of defined benefit plans declined from around 170,000 to less than 40,000. In the same period the number of defined contribution plans rose from 462,000 to over 700,000 (see Boender $\left.{ }^{1}\right)$.

The movement away from defined benefit plans to defined contribution plans has shifted

Correspondence: Nigel D. Lewis, Teacher Retirement System of Texas, 1000 Red River Street, Austin, Texas 78701-2698, USA.

Tel: 5125426400

Fax: 5123705144

E-mail: nigel.lewis@trs.state.tx.us the risk of having insufficient funds in retirement to the individual employee. With the technology boom and bust of the early 2000 s and credit crunch of late 2007 and 2008 came the wider realisation that many participants in self-directed retirement plans may not know enough to choose rationally among alternative investments. Munnell and Suden ${ }^{2}$ report failure to diversify and over investment in company stock as two of the most common investment mistakes. In response mutual fund companies have launched lifecycle investment funds (see Poterba et al. ${ }^{3}$ ).

Lifecycle investment funds are one of the fastest growing segments in the mutual fund industry. Assets under management have grown from around $\$ 1$ bn in 1996 to over $\$ 391$ bn by the end of 2007 (see FRC ${ }^{4}$ and ICI $^{5}$ ). Vanguard ${ }^{6}$ report rapid adoption of lifecycle investment funds in private-sector retirement plans. They are categorised into two distinct types, target risk funds and target date funds. Target risk funds account for 57 per cent of total assets in the lifecycle funds sector (see FRC ${ }^{4}$ and $\mathrm{ICI}^{5}$ ). They maintain a fixed asset allocation over time. 
Table 1: Glide path (proportion invested in equities) of four leading lifecycle investment providers ${ }^{a}$

\begin{tabular}{llllll}
\hline Target date & Barclays (\%) & Fidelity (\%) & Principal (\%) & Russell (\%) & Average (\%) \\
\hline 2010 & 45.0 & 52.6 & 50.4 & 25.5 & 43.4 \\
2020 & 64.6 & 69.3 & 63.6 & 44.7 & 60.5 \\
2030 & 78.9 & 81.7 & 74.1 & 78.8 & 78.4 \\
2040 & 90.8 & 84.4 & 82.1 & 86.3 & 85.9 \\
\hline
\end{tabular}

as of October 2007.

Investors choose the product that best matches their risk tolerance. For example, a younger worker might select a 80 per cent equity and 20 per cent fixed income product. While a worker close to retirement might select a 30 per cent equity and 70 per cent fixed income product.

Target date funds differ from target risk funds in that they deterministically vary the proportion that is held in stocks and in bonds. Asset allocation is changed according to a predefined 'glide path' that gradually tilts the asset mix away from equities towards bonds as the investor in the fund gets closer to retirement. Table 1 shows the equity glide path of four major US lifecycle investment fund providers. There is no agreed upon approach to the calculation of the equity glide path, the majority of funds have a large allocation in equities when the investor is young. This is gradually reduced as the participant draws closer to retirement. The rule used by lifecycle investment funds is a variant of the traditional rule of thumb that the percentage allocation to equities should be set to 100 minus the investors age in years (see Shiller ${ }^{7}$ ). The relationship between years to retirement and asset allocation using this rule is a straight line with a slope of one.

Over recent years there has been a proliferation of target date investment funds and their rate of growth is outstripping that of target risk funds. At the end of 2007 there were in excess of 250 target date funds (see FRC, ${ }^{4}$ ICI, ${ }^{5}$ Viceira ${ }^{8}$ and Ibbotson $^{9}$ ). They have gained rapid popularity because they simplify the investing process. New participants can sign up without significant knowledge of investing by answering the question 'when do I retire?' and choosing a fund with the closet retirement date. For example, Principal Financial Group offers lifecycle investment funds with target dates increasing in ten-year increments, 2010, 2020, 2030, 2040 and so on. A new participant expecting to retire in 2043 might select the 2040 fund.

Over the next decade or so, the first generation of Americans who have relied wholly or in part on self-directed retirement investments will begin to exit the labour market. Yet despite the growing importance of target date funds as retirement accumulation vehicles, there exists a paucity of literature on their role in retirement wealth creation. Theoretical and empirical support for the idea of lifecycle investing can be found in Bodie et al., ${ }^{10}$ Schooley and Worden, ${ }^{11}$ Jagannathan and Kocherlakota, ${ }^{12}$ Bodie and Crane,${ }^{13}$ Booth ${ }^{14}$ and Poterba et al. ${ }^{3}$ Lewis ${ }^{15}$ finds that risk averse investors should not necessarily choose lifecycle investment funds with a low allocation to equities. Byrne et al. ${ }^{16}$ investigate the cost of delaying contributions to a pension plan. Lewis et al. ${ }^{17}$ and Lewis ${ }^{18}$ outline a risk-based approach to enhance long-term performance and reduce risk of lifecycle investing. Benzoni et al. ${ }^{19}$ have questioned whether lifecycle investment is appropriate for retirement saving.

\section{Modelling retirement wealth creation}

A key issue in formulating investment strategies for managers of lifecycle funds is how aggressive or conservative they should be to maximise long-term wealth of fund participants. As shown in Table 1, equity glide paths can vary quite considerably between fund providers. To capture the dispersion in potential returns of different target date funds three representative equity glide paths, shown in Figure 1, are used in the analysis. The aggressive glide path allocates 100 per cent to equities with 35 years to retirement. Each year the equity allocation is adjusted downward until it reaches 50 per cent by retirement. 


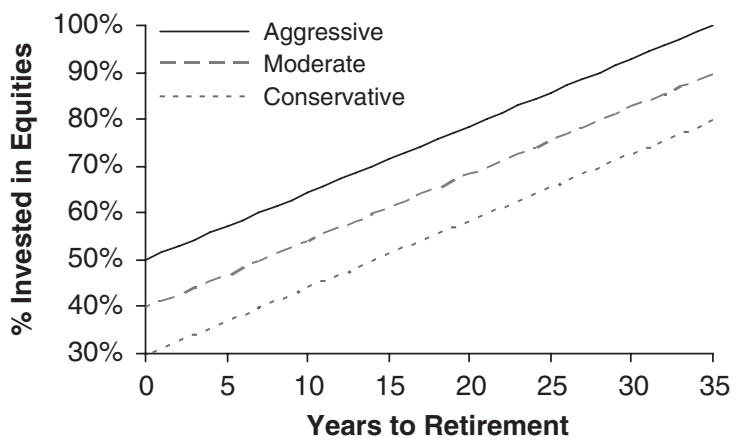

Figure 1: Representative glide paths used in the analysis

The moderate glide path initially allocates 90 per cent to equities and gradually adjusts down to 40 per cent by retirement. The conservative glide path allocates 80 per cent to equities declining to 30 per cent by retirement.

The evolution of a household's retirement savings over time depends on a large number of socio-economic factors as well as asset returns. Many individuals delay starting to contribute to their pension plan until well into their working life. This might be because they are paying off student loans or else waiting for their income to rise above some specific level. Our baseline case considers a male participant who has 35 years to retirement, with a salary of $\$ 40,000$ and initial retirement savings of $\$ 5,000$. We assume nominal wage growth of 5.5 per cent per annum. Munnell and Suden ${ }^{2}$ find that the typical contribution rate for a $401(\mathrm{k})$ participant is 6 per cent with an employer match of 3 per cent. Reflecting these numbers a contribution rate of 9 per cent is assumed. The fund invests in US equities and US Government long-term bonds.

Total accumulated savings at retirement can be used to purchase a single premium lifetime annuity that provides a level income for life. A combination of bootstrapped historical data and Monte Carlo simulation are used to estimate accumulated real savings for each of the glide paths. Inflation, denoted by $q_{t}$, is assumed to follow the Ornstein - Ulenbeck process

$$
d q_{t}=\kappa\left(\mu-q_{t}\right) d t+\sigma \varepsilon_{t} \sqrt{d t}
$$

Where $\varepsilon_{t}$ is the standard normally distributed random shock, $\kappa$ is the mean reversion parameter, $\mu$ is the equilibrium level of long run inflation and $\sigma$ is the long run volatility. Reflecting the historical US inflation estimates of Ahlgrim et al. ${ }^{20}$ the mean reversion parameter $\kappa$ is set equal to 0.4 , long run inflation $\mu$ to 4 per cent with $\sigma$ equal to 3 per cent.

Using the simulated terminal real wealth the probability distribution of the ratio of initial real retirement income to real salary immediately prior to retirement given present day annuity prices can be determined, ${ }^{21}$ this is known as the replacement ratio. A replacement ratio of 0.5 indicates that the participant will be able to replace 50 per cent of his final salary. Many defined benefit plans offer a replacement ratio of $1 / 60$ th of final pay for each year worked. Under such a plan, an individual with 35 years' service would receive a pension income of approximately 58 per cent of final salary. We use this ratio as a benchmark for the outcomes of the aggressive, moderate and conservative target date glide paths.

Table 2 shows the median replacement ratio for each of the glide paths based on 10,000 simulations. The replacement ratio ranges from 0.38 for the aggressive glide path to 0.33 for the conservative glide path. These differences are directly related to the average allocation to equities. The aggressive glide path has an average allocation of 75 per cent, while the moderate and conservative allocate 65 and 55 per cent, respectively. The higher expected return for equities relative to bonds explains the observed higher replacement ratio of the aggressive glide path.

As is evident from Table 2, the glide paths have differing levels of volatility risk. For the conservative glide path the inter-quartile range is $0.27-0.41$, the interpretation of which is that there is a 50 per cent probability of the outcome lying outside of this range. By contrast the aggressive glide path has almost the same lower bound but has an upper bound approximately 25 per cent higher at 0.52 . All three glide paths have a 5 per cent Value At Risk (VaR) of approximately 0.21 . The interpretation of this figure is that there is a one in 20 chance of the 
Table 2: Median replacement ratio for each of the target date glide paths

\begin{tabular}{llll}
\hline & Aggressive & Moderate & Conservative \\
\hline $\begin{array}{l}\text { Replacement } \\
\text { ratio }\end{array}$ & 0.38 & 0.36 & 0.33 \\
$\begin{array}{l}\text { Inter-quartile } \\
\text { range }\end{array}$ & $0.30-0.52$ & $0.29-0.46$ & $0.27-0.41$ \\
$5 \%$ VaR & 0.21 & 0.21 & 0.21 \\
\hline
\end{tabular}

individual receiving a replacement ratio of 0.21 or less.

Target date fund participants need to accumulate capital during their working years in order to generate sufficient income through retirement. Success will in large part be dependent on the choice of asset classes and allocation of funds between those asset classes over time. Over a time horizon of 30 years or more it is reasonable to expect that target date products with aggressive allocations to equities will generate on average greater retirement wealth than allocations with more conservative glide paths. The results seem to indicate that more aggressive glide path has very similar downside risks in terms of the inter-quartile range lower bound and 5 per cent $\mathrm{VaR}$ as moderate and conservative glide paths. Rather surprisingly the degree of $\mathrm{VaR}$ risk is similar across the various glide paths. This may have implications for the type of fund participants with long-time horizons should select as their target date fund.

The median replacement ratio of the aggressive glide path at 0.38 is only two points higher than the median replacement ratio of the moderate glide path. Indeed, all three glide paths deliver a median replacement ratio considerably lower than the 0.58 ratio an individual with 35 years' service to a defined benefit plan would expect to receive.

One way to increase the median replacement ratio is to delay retirement to a later age. Table 3 shows the impact on the replacement ratio of delaying retirement by five years to age 70 and ten years to age 75 . The median replacement ratio increases. For example, the income replacement ratio of the aggressive glide path rises from 0.38 for retirement at 65 to 0.48 and 0.57 for retirement at 70 and 75 , respectively. These are very significant increases. As a rule of thumb, the aggressive path delivers approximately an additional ten points for every five-year delay in retirement. As shown by the moderate and conservative glide paths, this rate of increase, however, appears to diminish somewhat over time. For example, the income replacement ratio of the moderate glide path rises as retirement is delayed. It, however, increases at a diminishing rate from 0.36 for retirement at 65 , to 0.44 and 0.50 for retirement at 70 and 75 , respectively. A similar pattern is observed for the conservative glide path. The difference between delaying retirement from five to ten years is nine points for the aggressive glide path, six points for the moderate glide path and only four points for the conservative glide path. It appears that the improvement in the replacement ratio from delaying retirement are highest with aggressive allocation to equities. The benefit diminishes quite rapidly from aggressive to moderate and conservative glide paths. Indeed, only the aggressive glide path delivers a replacement ratio close to the level an individual with 35 years' service to a defined benefit plan would expect to receive.

As shown in Table 3, delaying retirement reduces replacement ratio risk. The inter-quartile ranges shift upwards, as does the 5 per cent VaR. The aggressive glide path VaR appears to reduce replacement ratio risk by five points for every five years of delay in retirement. For example, at age $65 \mathrm{VaR}$ is 0.21 , at 70 it is 0.25 and at $75 \mathrm{VaR}$ is equal to 0.30 . This reduction in risk is less marked in the moderate glide path, where VaR risk declines by five points to 0.25 with a fiveyear delay and 0.27 with a ten-year delay.

An alternative to working longer and later in life is to increase the contribution rate. Table 4 shows the impact of various contribution rates on median replacement ratio for each glide path. The contribution rate required to match the replacement ratio of an individual with 35 years' service to a defined benefit plan is shaded. The aggressive glide path requires a contribution rate of at least 13 per cent, and the moderate and conservative glide paths require 15 and 16 per cent, respectively.

Given the current low contribution rates of employees into pension products, the question is 
Table 3: Median replacement ratio for each of the target date glide paths when retirement is delayed by 5 or 10 years

\begin{tabular}{|c|c|c|c|c|c|c|}
\hline \multirow[b]{2}{*}{ Delay } & \multicolumn{2}{|l|}{ Aggressive } & \multicolumn{2}{|l|}{ Moderate } & \multicolumn{2}{|c|}{ Conservative } \\
\hline & 5 years & 10 years & 5 years & 10 years & 5 years & 10 years \\
\hline Replacement ratio & 0.48 & 0.57 & 0.44 & 0.50 & 0.40 & 0.44 \\
\hline Inter-quartile range & $0.36-0.66$ & $0.3-1.11$ & $0.34-0.57$ & $0.27-0.97$ & $0.32-0.49$ & $0.24-0.84$ \\
\hline $5 \%$ VaR & 0.25 & 0.30 & 0.25 & 0.27 & 0.25 & 0.24 \\
\hline
\end{tabular}

how can individuals be helped to save at a higher rate for retirement? This issue is faced by Europe, United Kingdom as well as the United States. The low rate of retirement savings is primarily the result of a tendency to consume rather than save income. Part of the solution may well be mandating by law that everyone save a minimum proportion, say 15 per cent, of their gross salary to a retirement account. Helman and Paladino ${ }^{22}$ find that only 42 per cent of American workers have tried to calculate how much to save for retirement; and of those who have tried only 32 per cent cannot remember the results of their calculations.

To save for retirement successfully, employees need to improve their financial literacy. Critical to success is education of younger employees about meeting their retirement wealth objectives. It seems reasonable to suspect that a significant number of employees would take action if they had knowledge of the likely consequences of saving to little or choosing too conservative a target date fund. As the results show, not all target date funds are the same. The conservative glide path results in a lower replacement ratio and consequently a smaller retirement income. Easily accessible and freely available advice about retirement options maybe a prerequisite to more widespread success.

\section{Summary}

The findings of this paper have important implications for target date fund participants who are considering extending their working life in order to better fund their retirement. They also raise a number of issues for plan sponsors whose fiduciary duty is to select and offer a suitable line of target date products. It is clear from this research that target date participants need to start contributing to their $401(\mathrm{k})$ as soon as possible
Table 4: Median replacement ratio for differing contribution rates and each glide path

\begin{tabular}{clll}
\hline Contribution (\%) & Aggressive & Moderate & Conservative \\
\hline 9 & 0.38 & 0.36 & 0.33 \\
10 & 0.44 & 0.40 & 0.37 \\
11 & 0.48 & 0.44 & 0.40 \\
12 & 0.54 & 0.49 & 0.45 \\
13 & 0.57 & 0.52 & 0.48 \\
14 & 0.60 & 0.56 & 0.51 \\
15 & 0.61 & 0.57 & 0.53 \\
16 & 0.69 & 0.63 & 0.58 \\
\hline
\end{tabular}

if they are to accumulate sufficient wealth for retirement. When the rate of saving is insufficient deferring retirement by 5 or 10 years may have a positive impact on retirement wealth creation. Participants in target date funds with aggressive allocations to equities will, however, likely reap the most benefit in this situation. The analysis and results outlined in this paper may also assist investors, plan sponsors and policy makers in better understanding the risk-return characteristics of competing lifecycle investment products.

\section{References and Notes}

1 Boender, M. (2005) 'Increasing voluntary savings in the USA', Pensions, Vol. 11, pp. 65-80.

2 Munnell, A. and Sundén, A. (2006) '401(k) Plans Are Still Coming Up Short', Center for Retirement Research, Boston College, Boston, MA.

3 Poterba, J., Rauh, J., Venti, S. and Wise, D. (2006) 'Life-cycle asset allocation strategies and the distribution of $401(\mathrm{k})$ retirement wealth', NBER Working paper No. 11974, National Bureau of Economic Research, Cambridge, MA

4 FRC (2007) 'Lifecycle funds quarterly report', Financial Research Corporation. Boston, MA. 4(3).

5 ICI (2007) 'The US retirement market, 2006', ICI Research Fundamentals. Washington DC: Investment Company Institute. 16(3).

6 Vanguard Center for Retirement Research (2004) 'How America Saves: A Report on Vanguard Defined Contribution Plans', The Vanguard Group, Washington, DC.

7 Shiller, R. J. (2005) 'Life-cycle portfolios as government policy', The Economists' Voice, Vol. 2(1), Article 14, pp. 1-8.

8 Viceira, L. M. (2007) 'Life-cycle investment funds', Available at SSRN: http://ssrn.com/abstract $=988362$. 
9 Ibbotson (2008) 'Lifetime asset allocations: Methodologies for target maturity funds', Ibbotson Associates Research Report, Chicago.

10 Bodie, Z., Merton, R. C. and Samuelson, W. F. (1992) 'Labor supply flexibility and portfolio choice in a life-cycle model', Journal of Economic Dynamics and Control, Vol. 16, pp. 427-449.

11 Schooley, D. K. and Worden, D. D. (1999) 'Investors' asset allocations versus life-cycle funds', Financial Analysts Journal, Vol. 55, No. 5, pp. 37-43.

12 Jagannathan, R. and Kocherlakota, N. R. (1996) 'Why should older people invest less in stocks than younger people?' Federal Reserve Bank of Minnesota Quarterly Review, Vol. 20, No. 3, pp. 11-23.

13 Bodie, Z. and Crane, D. B. (1997) 'Personal investing: Advice, theory and evidence', Financial Analysts Journal, Vol. 53, No. 6, pp. 13-23.

14 Booth, L. (2004) 'Formulating retirement targets and the impact of time horizon on asset allocation', Financial Services Review, Vol. 13, No. 1, pp. 1-17.

15 Lewis, N. (2008) 'Assessing shortfall risk in life-cycle investment funds', Journal of Wealth Management, Summer, pp. 43-50.
16 Byrne, A., Blake, D., Cairns, A. and Dowd, K. (2006) 'There's no time like the present: The cost of delaying retirement saving', Financial Services Review, Vol. 15, pp. 213-231.

17 Lewis, N., Okunev, J. and White, D. (2007) 'Using a value at risk approach to enhance tactical asset allocation', Journal of Investing, Winter, pp. 17-26.

18 Lewis, N. (Forthcoming) 'Using value at risk to enhance asset allocation in life-cycle investment funds', Journal of Investing.

19 Benzoni, L., Collin-Dufresne, P. and Goldstein, R. S. (2005) 'Portfolio choice over the life-cycle in the presence of "trickle down” labor income', NBER Working paper No. 11247, National Bureau of Economic Research, Cambridge, MA.

20 Ahlgrim, K. C., D’Arcy, S. P. and Gorvett, R. W. (2005) 'Modeling financial scenarios: A framework for the actuarial profession', Proceedings of the Casualty Actuarial Society Casualty Actuarial Society, Arlington, Virginia.

21 Price of annuity taken from Principal Financial Group quote mid-November 2007.

22 Helman, R. and Paladino, V. (2004) 'Will Americans ever become savers?', EBRI Issue Brief No. 268, April 2004, p. 9. 